\title{
Guidance for wiki-supported collaborative learning and community knowledge building for an entire class: Enhancing learning environments during the COVID19 pandemic
}

\author{
Orientación para el aprendizaje colaborativo apoyado en wiki y \\ para la construcción de un conocimiento comunitario en toda la \\ clase: Mejora de entornos de aprendizaje en un contexto COVID19
}

\author{
Chun-Yi Lin \\ National Taiwan Normal University. Taipei, Taiwan \\ chunylin@ntnu.edu.tw \\ Charles M. Reigeluth \\ Indiana University. Bloomington, USA \\ reigelut@indiana.edu
}

\begin{abstract}
The purpose of this study is to develop an instructional theory for scaffolding wiki-supported collaborative learning in small group projects and in collaborative knowledge development for undergraduate courses. The paper presents the instructional theory developed through two implementations and discusses how this instructional theory may enrich learning regardless of the constraints during the COVID19 pandemic, in which small-group meetings are possible but large-class meetings are moved online.

Although, in theory, wikis should be a powerful technology to support collaborative learning, empirical research reveals challenges regarding student motivation, group dynamics, and assessment. To bridge the gaps between theory and practice, we used the design-based research approach (DBR) and collaborated with two expert practitioners to develop the instructional theory. The research process includes an initial theory, implementations in two cases, and theory refinement. Data collection and analysis involve literature review, multiple individual interviews with experts before and during implementations, weekly class observations, focus-group interviews with students during implementation, content analysis of class wikis, and focus-group interviews with experts for theory refinement.

The results of the study presented in this paper focus on the refined instructional theory, which was grounded in theoretical work, expert instructors' heuristic knowledge, and local effectiveness. In addition, this paper includes design principles with some considerations to support learning in COVID19 environments. In other words, the success of using wikis to foster a culture of sharing, and to increase student motivation and participation in individual or group project work,
\end{abstract}


as well as in community knowledge building for an entire class, may enrich learning during the pandemic by creating learner-centered, knowledge-centered, assessment-centered, and community-centered learning environments.

Keywords: community knowledge building, the COVID19 pandemic, designbased research, instructional theory, wikis for collaborative learning

\section{Resumen}

El propósito de este estudio es desarrollar una teoría de instrucción para el aprendizaje colaborativo, apoyado por wiki, en proyectos de grupos pequeños y en el desarrollo de conocimiento colaborativo para cursos de pregrado. El artículo presenta una teoría de la instrucción desarrollada a través de dos implementaciones y analiza cómo esta teoría de la instrucción puede enriquecer el aprendizaje independientemente de las limitaciones durante la pandemia de COVID19, en la que las reuniones de grupos pequeños son posibles pero las reuniones de clases grandes se trasladan a educación en línea.

Aunque, en teoría, los wikis deberían ser una tecnología poderosa para apoyar el aprendizaje colaborativo, la investigación empírica revela desafíos con respecto a la motivación de los estudiantes, la dinámica de grupo y la evaluación. Para cerrar las brechas entre la teoría y la práctica, utilizamos el enfoque de investigación basado en el diseño (DBR) y colaboramos con dos profesionales expertos para desarrollar la teoría de la instrucción. El proceso de investigación incluye una teoría inicial, implementaciones en dos casos y refinamiento de la teoría. La recopilación y el análisis de datos incluyen la revisión de la literatura, múltiples entrevistas individuales con expertos antes y durante las implementaciones, observaciones semanales de la clase, entrevistas de grupos focales con los estudiantes durante la implementación, análisis de contenido de los wikis de la clase y entrevistas de grupos focales con expertos para perfeccionar la teoría.

Los resultados del estudio presentado en este artículo se centran en la teoría de la instrucción refinada, que se basa en el trabajo teórico, el conocimiento heurístico de los instructores expertos y la eficacia local. Además, este documento incluye principios de diseño con algunas consideraciones para apoyar el aprendizaje en entornos COVID19. En otras palabras, el éxito de usar wikis para fomentar una cultura de compartir y para aumentar la motivación y participación de los estudiantes en el trabajo de proyectos individuales o grupales, así como en la construcción de conocimientos comunitarios para toda una clase, puede enriquecer el aprendizaje durante la pandemia al crear entornos de aprendizaje centrados en el alumno, centrados en el conocimiento, centrados en la evaluación y centrados en la comunidad.

Palabras clave: construcción de conocimiento comunitario, la pandemia de COVID19, investigación basada en el diseño, teoría de la instrucción, wikis para el aprendizaje colaborativo

Guidance for wiki-supported collaborative learning and community knowledge building for an entire class: Enhancing learning environments during the COVID19 pandemic. Chun-Yi Lin and Charles M. 


\section{Background}

\section{The COVID-19 Pandemic Situation}

The COVID-19 pandemic has resulted in many school closures to prevent infection and illness. Globally, the pandemic has affected up to $90 \%$ of total enrolled learners this year (UNESCO, 2020). In higher education, many students have no choice but to take online classes or hybrid classes depending on the numbers of reported COVID-19 cases regionally and nationally. Although many instructors have transitioned their courses online in a very short time, some students have found it convenient to learn without taking the health risk, but some students have felt isolated and hoped for more peer interaction to engage learning.

When classes become pre-recorded and delivered to students, it is more challenging to produce high quality interaction to promote higher-order thinking than it would be in faceto-face settings. Without being able to observe or respond to each other's verbal and nonverbal expressions, it is difficult for students and instructors to develop the landscape view of a class regarding learning progress and atmosphere, or to know about and connect what one is learning to students' personal interests. In addition, how to scaffold learning during a project-based learning process and how to foster a sense of community through peer learning and knowledge building are important challenges to overcome to enrich learning during emergency remote teaching.

\section{The Wiki Learning Environment}

Wikis ${ }^{1}$ are a unique Web tool featuring massive collaboration as users browse and edit its content, review the edit history, compare versions, and communicate with other users. Wikis may offer an environment to foster collaborative, constructive, and customized learning experiences when instructional methods are designed and implemented carefully.

\section{Purpose of Study}

This study entailed collaborating with practitioners to develop an instructional theory to guide the integration of wikis into undergraduate coursework to support collaborative learning. Thus, design-based research (DBR) and heuristic task analysis (HTA) were used to investigate the main research question: How could wikis be effectively integrated into higher education classrooms to support collaborative learning? The following sub-questions guided the study:

1. Initial theory: Based on a literature review and experts' input, what might the initial version of the instructional theory be like? How do the instructors use the instructional theory,

\footnotetext{
${ }^{1}$ Several platform services are available to support educational wikis, such as PBworks and Google Sites. Besides, Wikimedia offers a free wiki software, Mediawiki, to be installed and hosted on users' own servers.
}

Guidance for wiki-supported collaborative learning and community knowledge building for an entire class: Enhancing learning environments during the COVID19 pandemic. Chun-Yi Lin and Charles M. Reigeluth. 
modify its methods, and implement it in classrooms? What heuristic knowledge underlies the instructors' performances?

2. Refined theory: What might a refined instructional theory look like to support learning in COVID19 environments?

\section{Literature Review}

This section presents a literature review of wiki-supported collaborative learning, including the following subsections: Wikis' unique features for student learning, challenges during the wiki collaboration process, and theoretical perspectives of collaborative learning on wikis.

\section{Wikis' Unique Features for Student Collaboration}

Wikis are identified as a powerful tool for supporting collaborative learning, as wikis allow users to collaborate without constraints of time and space, to communicate through asynchronous tools, to document all revisions and revert to previous versions when needed, and to edit with a simple interface and tools, especially on wiki servers targeted for educational uses. Wikis have been integrated into higher education classrooms to support some exciting projects, proving their usefulness for academic collaboration across or within certain disciplines (Berthoud \& Gliddon, 2018; Trocky \& Buckley, 2016).

Most importantly, when researchers compare collaboration on wikis with traditional methods, evidence shows that wikis support collaborative learning better. For instance, compared to traditional collaborative writing methods used in courses, de Pedro et al. (2006a) conclude that the wiki method with some proposed adjustments may increase the efficiency of writing collaboratively. Both students and faculty in their study praised the convenience and power of open access in the collaborative writing process. Additionally, compared to discussion boards or threads, wikis are perceived as an innovative and transformative tool for collaboration by students because individuals contribute to content publicly and in a timely manner, and the process of dynamic editing forces consensus building as students actively revise previous written texts (Hemmi, Bayne, \& Land, 2009).

\section{Challenges during the wiki collaboration process.}

Empirical research suggests issues that influence use of wikis for student collaboration, including group dynamics, student motivation, and assessment.

1. Group dynamics. Several studies on how wikis are used to support collaborative learning address concerns about the development of group dynamics, including quality peer interaction. Researchers generally use either a case study or a survey approach to investigate issues of wiki implementation and propose ideas for future improvement in their discussion. These types of research are intended to understand the class wiki phenomenon or to test

Guidance for wiki-supported collaborative learning and community knowledge building for an entire class: Enhancing learning environments during the COVID19 pandemic. Chun-Yi Lin and Charles M. Reigeluth. 
existing learning theories, rather than to develop instructional theories that guide practitioners to integrate wikis into higher education classrooms (West \& West, 2009), including how to establish group dynamics that support wikis.

It has been suggested that group dynamics is the key to success in collaborative learning on wikis, and its importance is identified in several studies through interviews and surveys with students and instructors. First of all, Bold (2006) found that students desire quality interaction to support group dynamics, and that it is often missing from the class wiki and perceived as a tradeoff for the convenience of working online. Second of all, poor group dynamics due to insufficient trust built in advance could lead to failure, as several student groups complained about unequal workload when asked to contribute to the wiki projects without adequate communication in face-to-face settings (Elgort, Smith, \& Toland, 2008). For the same reason, student teams could fail to operate as a group if consensus was not achieved in class (Robertson, 2008). Third of all, some instructors report their struggle with the lack of effective strategies for facilitating group-process skills (de Pedro et al., 2006b). Fourth of all, some instructional methods for developing group dynamics and coping with these problems are proposed in an instructional theory of wikis for collaborative learning (West \& West, 2009), such as helping groups to recognize and resolve conflicts by hosting a chat session with group members. However, the instructional theory is neither grounded in rigorous research methods nor supported by empirical evidence. Thus, more effort in developing and validating instructional methods is needed to increase the possibility that group dynamics can be properly established for wikis.

A platform, such as wikis, for enabling collaboration does not work magically. As Robertson (2008) states, "unsurprisingly, wikis are not a solution to difficulties associated with group-based assignments," without providing appropriate pedagogical support for both practitioners and students. Some researchers attribute the quality of interaction and group dynamics to communication channels (Elgort et al., 2008) or to group characteristics (de Pedro et al., 2006b), but more importantly, findings imply the need for developing effective instructional methods from existing literature and practitioners' expertise in the area, such as the significant role that teachers play in designing and facilitating collaborative tasks on wikis. In short, effective group dynamics need to be carefully fostered as one of the important goals to pursue in the instructional theory.

2. Issues of student motivation. Several motivational issues that students encounter in collaborative wiki tasks have been identified in studies. Students' resistance to participation may be attributed to students' technological anxieties, the lack of time for developing intrinsic motivation or fostering a culture change, the lack of a sense of shared ownership in written work, and the unclear connection between wiki activities and students' perceived immediate usefulness for learning. Among the studies reviewed, most researchers have integrated an understanding of motivation into teaching to explore these motivational issues for students

Guidance for wiki-supported collaborative learning and community knowledge building for an entire class: Enhancing learning environments during the COVID19 pandemic. Chun-Yi Lin and Charles M. Reigeluth. 
using wikis. Still, literature in other relevant fields can contribute to theory development, and practitioners' expertise can validate strategies regarding how to maintain student motivation.

The first motivation-related issue is students' anxieties or uncertainty surrounding wikis. Since these negative feelings influence students' motivation to participate, Schacht (2007) created tutorial videos that not only provided customized technological support to increase confidence in using wikis, but also allowed him as teacher to use class time for maintaining students' excitement in the subject matter. In addition to students' anxieties with technology, their level of uncertainty was raised because of the relative lack of structure in wikis when compared to instruction in traditional classrooms. To find the balance between instructor control and student control, it is suggested that instructors ask students what level of structure they need (Bonk, Lee, Kim, \& Lin, 2010). However, more detailed advice is needed to guide practitioners regarding how to gradually remove scaffolding as they assist students moving from structured to self-organized inquiry on wikis.

The second motivation-related issue is lack of ownership during the collaborative writing process on wikis. Several studies revealed students' reluctance to edit each other's work, although students appreciate the shared space for writing. Among all rival explanations and possible solutions, it appears that gaining a fundamental understanding of collaborative writing tasks, including Saunders' (1989) work on this subject, would help the theory development regarding how to enhance students' ownership of written texts in order to maximize participation by having students collaborate at most writing stages.

The third issue relating to improving student motivation is a lack of time to develop a culture change and students' intrinsic motivation. Since students who are intrinsically motivated become central and prominent contributors in online collaborative learning environments (Rienties, Tempelaar, Van den Bossche, Gijselaers, \& Segers, 2009), Ebner, Kickmeier-Rust, and Holzinger (2008) attempted to create an open learning environment on wikis by removing external incentives, but failed to engage students in active participation due to the lack of time for developing a "give-and-take" culture. Therefore, it is necessary to develop strategies, such as student reflection on wiki activities (West \& West, 2009), to enhance students' intrinsic motivation and to facilitate the culture change. Reviewing literature and studying practitioners' expertise is also an important part of this development process.

Lastly, the unclear connection between wiki activities and students' perceived usefulness in learning may decrease students' willingness to participate on wikis. Students are not motivated to use a class wiki when they fail to see the immediate benefits for learning because they perceive social technologies in educational contexts as different from social technologies in personal use. Students' perceived usefulness of wikis may be directly linked to assessment structure, academic achievement, and satisfaction from interactive learning (Cole, 2009). In addition to developing intrinsic motivation, interactive learning, if carefully fostered and situated in activities, can support meaningful collaborative learning. Interactive

Guidance for wiki-supported collaborative learning and community knowledge building for an entire class: Enhancing learning environments during the COVID19 pandemic. Chun-Yi Lin and Charles M. Reigeluth. 
learning, from a learner's perspective, is not necessarily associated with the interactive nature of wikis. According to Cole's analysis, there is a need to enhance student motivation and engagement by designing and using an instructional theory that offers methods (a) to support meaningful collaborative learning on wikis and (b) to help students perceive the usefulness of wikis.

In summary, technology may bring excitement to learning, but students' long-term engagement is not guaranteed. The kind of knowledge needed here is how to help students transform into active learners who are aware of:

- being placed in a less-structured learning environment,

- their responsibilities in online collaborative learning, and

- the importance of self-directed participation in learning communities.

3. Issues of assessment. Assessing students' collaborative work on wikis has been studied due to its complexity and important influence on student participation. Some firsttime wiki educators may struggle with assessment. Schacht (2007) was concerned with the design of assessment of group work on wikis. For instance, to guide group efforts, he gave suggestions on the wiki discussion pages, but his suggestions only had a minor impact. In this case, a fundamental understanding of the assessment of cooperative learning, such as the significance of group members' interdependence, may suggest an effective method to resolve some of these concerns.

In addition to challenges that instructors face, students also struggle with the assessment of wiki group work. Students may hold back peer editing for assessment's sake because they worry about "messing around" with someone's work (Hemmi et al., 2009). Since wiki content can be constantly changed by others, students' sense of ownership in written texts and interdependence in collaborative work assessment become particularly important and may influence their willingness to edit peers' work. Thus, West and West (2009) suggest making assessment policies or grading schemes explicit to students in order to encourage participation. The challenges discussed show the crucial role that assessment plays in wiki integration for collaborative learning.

Finally, a common issue of wiki assessment is that it is time-consuming for instructors (de Pedro et al., 2006a; de Pedro Puente, 2007) to analyze student contributions, since most wiki servers do not generate all the data needed for assessment. Therefore, both effectiveness and efficiency aspects of wiki assessment methods need to be advanced through a better understanding of the relevant literature and from practitioners' expertise.

\section{Theoretical Perspectives of Collaborative Learning on Wikis}

Wikis have drawn educators' attention for integration into courses especially for wikis' capability to support collaborative learning, perhaps because of the importance of collaboration and shared responsibilities, which are characteristics of the learner-centered

Guidance for wiki-supported collaborative learning and community knowledge building for an entire class: Enhancing learning environments during the COVID19 pandemic. Chun-Yi Lin and Charles M. Reigeluth. 
paradigm of education and are widespread in the workplace. Therefore, in addition to wikis' unique features, these characteristics lead to another reason for wikis' importance to the new paradigm of instruction, which is the philosophical and practical maturity of collaborative learning in higher education.

Collaborative learning has become widespread in higher education not only because of its prevalence in the workplace, but also because of its profound theoretical background in Dewey's and Vygotsky's work. In addition, there is much empirical evidence of its effectiveness for enhancing students' higher-order thinking, creative thinking, and self-values (i.e., self-esteem, self-efficacy, and values). Given its effectiveness, collaborative learning led to higher academic achievement and greater enjoyment when compared to competitive and individualistic learning experiences (Johnson \& Johnson, 1989; Nichols \& Miller, 1994). Matthews, Cooper, Davidson, and Hawkes (1995) call for broader awareness of both collaborative and cooperative learning in higher education because of:

(1) their shared beliefs and assumptions, such as actively involving students in learning experiences with their responsibilities as an individual and as a member of a group, developing higher-order thinking by articulating ideas in small groups and applying knowledge, valuing diversity, and increasing students' success and retention by working in groups, and

(2) the similar challenges that practitioners face, such as students' resistance to an active approach and teachers' fear of not covering all the material.

Thus, collaborative learning is defined, for the purpose of this dissertation study, and from a broader view of the theoretical and practical perspectives of collaborative learning and cooperative learning in higher education, according to Panitz (1996), as a philosophy that believes in active learning in groups with respect for individuals and in shared responsibilities to reach consensus in the knowledge-building process. Collaborative learning, when broadly defined, includes contextual variations that reflect individual instructors' areas of interests or concerns, such as different levels of teacher involvement, different foci of group outcomes, and differences regarding the need for group training (Matthews et al., 1995).

In conclusion, given that wikis offer opportunities to create customized, constructive, and collaborative learning experiences that college students need in the learner-centered paradigm, wikis for collaborative learning within the new paradigm of instruction are important and influential. Garrison and Aykol (2009) state that collaborative constructivist ideas and emerging instructional technologies have begun transforming higher education. We think that wikis can support student development in three aspects: (1) in cognition, through interaction with content, peers, and instructors, and the process of consensus building, (2) in group skills, through collaboration with fewer constraints from time, space, and course structure, and through the processes of collaborative problem-solving and decision-making, and (3) in metacognition, by helping students become self-directed learners through contributions to self-selected content, awareness of self-strengths and weaknesses, and

Guidance for wiki-supported collaborative learning and community knowledge building for an entire class: Enhancing learning environments during the COVID19 pandemic. Chun-Yi Lin and Charles M. Reigeluth. 
monitoring their own contributions.

\section{Summary}

Wikis bring opportunities for collaborative learning in an open platform without time and space constraints. However, integrating wikis into courses can be complex and challenging in practice; issues revealed from empirical studies include a lack of effective strategies to foster group dynamics, motivate self-directed participation, and assess collaborative learning on wikis. These prior studies provide valuable lessons but also reveal inadequate knowledge to meet practitioners' needs for guidance in how to integrate wikis to support collaborative learning. The findings present common problems of wiki integration and suggest directions for future improvement. However, a comprehensive theoretical understanding in the relevant fields is needed to create plans for possible solutions. For example, the literature on collaborative writing tasks may contribute to the development of strategies for enhancing quality interaction in wiki activities, and literature on assessing group work may guide the design of wiki assessment methods. In conclusion, there is a need for an instructional theory that provides a set of methods and principles to help future educators effectively integrate wikis into classrooms. The theory needs to be not only grounded in a fundamental understanding of prior educational theories, but also validated by implementation and practitioners' expertise.

\section{Research Methods}

\section{Design-based Research}

Design-based research (DBR), also called design research, development research, or formative research, has been implemented for decades to sustain innovative development through a collaborative process among researchers and practitioners (Bereiter, 2002; DesignBased Research Collective, 2003). Different from traditional scientific approaches, which focus on designing and controlling variables to test hypotheses, DBR places emphasis on the process of working with practitioners in order to develop an instructional theory that works best in authentic settings. Wang and Hannafin (2005) identify nine important principles for planning and implementing DBR, which guided the research methods for this study:

1. Support design with research from the outset. First, the researchers identified resources, including theoretical work and design cases, for the specific topic.

2. Set practical goals for theory development and develop an initial plan. Practical goals helped the researchers focus on solving particular problems as we drafted an initial plan.

3. Conduct research in representative real-world settings. The researchers conducted DBR in the contexts that represent typical settings, and did not oversimplify the contexts.

Guidance for wiki-supported collaborative learning and community knowledge building for an entire class: Enhancing learning environments during the COVID19 pandemic. Chun-Yi Lin and Charles M. Reigeluth. 
4. Collaborate closely with participants. The researchers worked closely with practitioners to ensure the practicability of the instructional theory, and to improve the design both before and during implementation. As Wang and Hannifin (2005) point out, researchers should not cause the research findings directly, and researchers' efforts should go beyond immediate influence. In other words, the findings were grounded on the practitioners' implementation in authentic settings.

5. Implement research methods systematically and purposefully. Multiple methods for data collection and data analysis were used in DBR, including interviews, observations, content analyses, and other methods. The research methods were used systematically and purposefully to avoid discarding an enormous amount of data later during analysis.

6. Analyze data immediately, continuously, and retrospectively. The researchers continuously and simultaneously collected and coded data for generating design principles and triangulating data from multiple sources at different points of time.

7. Refine designs continually. The researchers refined the design continually in the iterative process of design cycles to resolve the problems and reach the design goals.

8. Document contextual influences with design principles. Given that DBR was implemented in local settings, the design principles, which were extracted from metadesign knowledge, should be interwoven with the contextual knowledge. In this way, the principles are not limited to applications in local settings but can be valuable to other designers.

9. Validate the generalizability of the design. As traditional instructional design focuses on design effectiveness in local settings, Wang and Hannafin (2005) state that DBR "strives to balance local effectiveness with design principle and theory development" (p. 19). Therefore, the generalizability of the design is established through a balance of consistent design goals with an emphasis on theory development and local effectiveness in grounded implementation with an emphasis on contextual design principles.

Although the DBR principles have provided practical advice on how DBR should be conducted in this study, there is insufficient detail on how to extract practitioners' heuristic knowledge (which is often tacit) to construct a design theory. Research on expertise shows that an expert's heuristic knowledge is essential to teach the less experienced to excel at a complex task in a short period of time (Bruning, Schraw, Norby, \& Ronning, 2003). Given that development of heuristic knowledge often involves years of practitioner experience, methods that can guide researchers to extract such knowledge and develop design theory that can benefit other practitioners are important. Therefore, this study integrated another methodological approach, heuristic task analysis, to DBR in order to develop the instructional theory with design principles.

Guidance for wiki-supported collaborative learning and community knowledge building for an entire class: Enhancing learning environments during the COVID19 pandemic. Chun-Yi Lin and Charles M. Reigeluth. 


\section{Heuristic Task Analysis}

In this study, one of the goals is to study how expert instructors integrate wikis in higher education classrooms, which involves mostly heuristic tasks; therefore, how to study experts' tacit knowledge underlying their performance becomes important. Heuristic tasks are defined as "tasks for which experts use causal models-interrelated sets of principles and/or guidelines - to decide what to do when ..." (Reigeluth, 1999a, p. 435).

Heuristic task analysis (HTA) is a methodology used for eliciting, analyzing, and representing expertise in performing complex heuristic tasks (Lee \& Reigeluth, 2009). Even though HTA is developed to elicit experts' tacit knowledge, the methodology also identifies explicit knowledge (Reigeluth, Lee, Peterson, \& Chavez, 2003). Reigeluth first presented HTA in 1999. Several formative research studies have been conducted to advance the methodology (Reigeluth, Lee, Peterson, \& Chavez, 2000; Lee \& Reigeluth, 2003; Lee \& Reigeluth 2009). The HTA methodology provides guidance on how to extract multiple experts' heuristic knowledge when the experts' behaviors may have become automated (unconscious) to perform complex and ill-structured tasks. The researchers adjusted some of the steps in the original HTA process to meet the needs of this study and to better integrate HTA into DBR. More details about the research process can be found later in the procedure section.

\section{Participants}

The participants in this study included: (1) Two expert instructors who had implemented wikis for collaborative learning in higher education institutions in Canada; (2) 16 undergraduate students who enrolled in the classes and volunteered to participate in the focus-group interviews; and (3) other instructors, whose students collaborated on the same class wiki with Expert B's students.

\section{The Methodological Framework}

Figure 1 presents the methodological framework of the research design. The framework guided the whole study, including the research methods, the data analyses, and the report of findings. This paper focuses on reporting major findings in Phase III. Information regarding the local evidence in Case 1 and Case 2 can be found in our previously published articles (Lin \& Reigeluth, 2016; Lin \& Reigeluth, 2019).

Guidance for wiki-supported collaborative learning and community knowledge building for an entire class: Enhancing learning environments during the COVID19 pandemic. Chun-Yi Lin and Charles M. Reigeluth. 


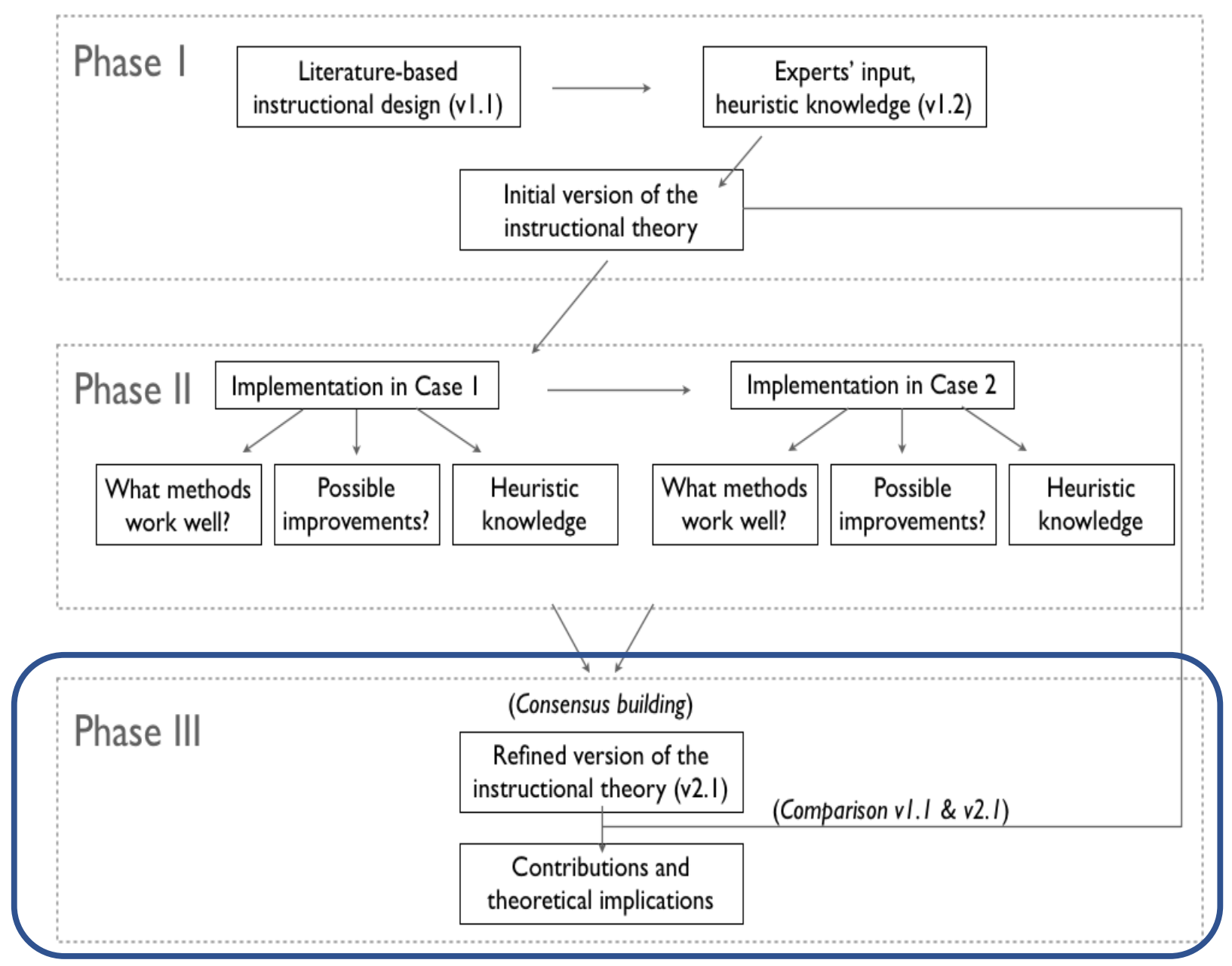

Figure 1. A methodological framework of the research design

\section{The Procedure for Data Collection and Analyses in Phase III}

The overall research study includes three phases: Phase I: development of the instructional theory, Phase II: implementation of the instructional theory and its iterative process in the individual cases, and Phase III: revisions to the instructional theory, its contributions and implications. This section describes the data collection and analysis in Phase III.

In Phase III, the research focus was shifted from the case level in Phase II to the designtheory level. The goals in this phase included (1) To develop the refined version of the design theory (v2.1) with methods and principles, and (2) to offer theoretical and practical implications. The following steps were taken during the Phase-III process:

1. Focus-group interview with instructors (Step III.1). After the implementations, a handout of findings from each case was prepared for the focus-group interview with both expert instructors. A 120-minute focus-group interview was conducted to improve

Guidance for wiki-supported collaborative learning and community knowledge building for an entire class: Enhancing learning environments during the COVID19 pandemic. Chun-Yi Lin and Charles M. Reigeluth. 
the initial instructional theory by reaching consensus on the refined instructional theory through discussions about implementation in the local settings. In this step, it was important to bring the instructors' attention from their implementation to the instructional theory. The researcher took field notes on, audio recorded, and transcribed the interview for analysis. The refined version of the instructional theory (v2.1) was created with rationales for changes and member-checked by the instructors (Step III.3).

2. Document analysis/ literature review (Step III.2). The goal of this step was to identify the contributions of this study to the literature, which included theoretical implications. To achieve this goal, the researcher compared the rationales or casual models related to the initial instructional theory (v1.1) with the findings presented in the refined instructional theory (v2.1). The researcher reviewed the changes in the methods and design principles, conducted a second round of literature review to better understand the relationships between the findings and prior research as well as theoretical contributions and implications.

3. Member-checking (Step III.3). The last step of the data collection and analyses was member-checking to ensure the accuracy of data and interpretations. The report was therefore sent to the instructors for review.

Note that the researchers added descriptions of v2.2 of the theory and discussions regarding use of the theory in COVID-19 situations, in consideration of the goal to enrich learning under the constraint of avoiding risking the health of university students, faculty, and staff.

\section{Findings}

The findings presented here include two parts: (1) Refined instructional theory (v2.1) based on two implementations prior to the COVID19 lockdown and the proposed instructional methods for scaffolding collaborative learning in COVID-19 situations (v2.2); and (2) Commentary on the revised methods (in v2.1) and the proposed methods (in v2.2).

\section{Refined Theory (v2.1) and the Proposed Methods for COVID-19 situations (v2.2)}

Table 1 below presents the changes made to the instructional theory throughout the development process. For readers' convenience, you may use the first column only and skip the additional columns for easy reference to the refined theory, especially for educators or instructional designers who are interested in using the refined instructional theory to guide their design and implementation of class wikis. On the other hand, readers who are interested in theory development and rationales may find all columns useful. The first column lists each instructional method; the second column shows the methods (v1.1) developed based on the relevant literature; the third column shows the methods (v1.2) refined after the individual

Guidance for wiki-supported collaborative learning and community knowledge building for an entire class: Enhancing learning environments during the COVID19 pandemic. Chun-Yi Lin and Charles M. Reigeluth. 
interviews and the first focus-group interview; the fourth (C1) and the fifth (C2) columns show the methods implemented in the two cases; and the last two columns show the refined methods (v2.1) after experts' consensus building in the second focus-group interview, as well as the methods to be considered for the pandemic situation (v2.2) proposed by the researchers.

\section{Pre-conditions}

The following are the preconditions for use of this instructional theory. Generalization beyond these preconditions requires additional research.

- Learners: Students who are enrolled in an undergraduate course

- Pedagogical approach: small-group or individual project-based collaborative learning, and knowledge building for an entire class (Situation: If collaboration among multiple classes and instructors is desired, effective communication is essential to ensure a shared vision to foster community knowledge building on one wiki)

- Learning environments for V1.1, V1.2, C1, C2, V2.1: A blended learning setting, including an offline face-to-face setting (computer access preferred) and an online class wiki, which offers a space for collaboration beyond the regular class meetings

- Learning environments for V2.2, the pandemic situation: A blended learning setting if possible, including offline, face-to-face, "small-group" meetings, and an online class wiki for collaboration beyond regular class meetings. The tasks may include smallgroup or individual projects and a whole-class community knowledge-building project.

\section{Instructional Methods}

The instructional methods in this theory are shown in Table 1. We place the key before the table for your convenience.

Key:

- The " $\mathrm{v}$ " indicates existence of a method (remained, implemented, or added).

- $~ " v / p "$ indicates partial implementation of a method.

- The " $\mathrm{n}$ " indicates the need to add a new method.

- The "blank" indicates non-existence of a method (deleted or not implemented).

- The " $\mathrm{s}$ " indicates a situationality: a method to be implemented based on the situation

- The "*" indicates rationales available (rationales for v2.1 are available in the commentary)

Table 1.

Instructional Methods (All Versions)

\begin{tabular}{|l|l|l|l|l|l|l|}
\hline Method & V1.1 & V1.2 & C1 & C2 & V2.1 & V2.2 \\
\hline $\begin{array}{l}\text { M1 Prepare the course objectives, the collaborative } \\
\text { projects, and the class wiki site }\end{array}$ & V & V & V & V & V & V \\
\hline
\end{tabular}

Guidance for wiki-supported collaborative learning and community knowledge building for an entire class: Enhancing learning environments during the COVID19 pandemic. Chun-Yi Lin and Charles M. Reigeluth. 


\begin{tabular}{|c|c|c|c|c|c|c|}
\hline Method & V1.1 & V1.2 & C1 & $\mathrm{C} 2$ & V2.1 & V2.2 \\
\hline $\begin{array}{l}\text { M1.1 Identify course objectives and other conditions, } \\
\text { such as learners' backgrounds }\end{array}$ & v & $v$ & $v^{*}$ & v & v & v \\
\hline $\begin{array}{l}\text { M1.2 Plan collaborative projects or tasks for helping } \\
\text { students achieve course objectives }\end{array}$ & v & $v$ & v & v & v & v \\
\hline $\begin{array}{l}\text { M1.2.1 Decide on individual small exercises, group } \\
\text { projects, or both }\end{array}$ & & $v^{*}$ & v & $\mathrm{v} / \mathrm{s}^{*}$ & $\mathrm{v} / \mathrm{s}$ & v \\
\hline $\begin{array}{l}\text { M1.2.2 Establish multiple project stages or } \\
\text { milestones for complex tasks }\end{array}$ & & & $v^{*}$ & v & $v^{*}$ & v \\
\hline $\begin{array}{l}\text { M1.3 Prepare the materials and the class wiki site } \\
\text { based on the objectives and needs of the collaborative } \\
\text { projects }\end{array}$ & v & $v^{*}$ & $v^{*}$ & v & v & v \\
\hline $\begin{array}{l}\text { M1.3.1 Create a framework and skeletal structure } \\
\text { on wiki to foster mutual understanding and } \\
\text { encourage leadership }\end{array}$ & & $v^{*}$ & v & v & $v$ & v \\
\hline $\begin{array}{l}\text { M1.3.2 Include diverse examples of community- } \\
\text { building tasks on wiki }\end{array}$ & & & n & v & $v^{*}$ & v \\
\hline $\begin{array}{l}\text { M1.4 For small classes, consider building a large } \\
\text { community on wiki by collaboration with multiple } \\
\text { sections }\end{array}$ & & & & v & $v / s^{*}$ & $v^{*}$ \\
\hline $\begin{array}{l}\text { M2 Introduce wikis to students and build their confidence } \\
\text { in using wikis }\end{array}$ & v & $v$ & v & v & v & v \\
\hline M2.1 Explain purposes of using wikis & v & v & v & v & v & v \\
\hline $\begin{array}{l}\text { M2.1.1 Explain connections between wiki projects } \\
\text { and academic goals }\end{array}$ & $v^{*}$ & $v$ & $v / p$ & v & v & v \\
\hline $\begin{array}{l}\text { M2.1.2 Explain advantages of using wikis compared } \\
\text { to using learning management systems }\end{array}$ & & $v^{*}$ & $v^{*}$ & $v / p$ & v & v \\
\hline M2.2 Introduce wiki concepts & $\mathrm{v}$ & v & $v^{*}$ & $v^{*}$ & v & v \\
\hline $\begin{array}{l}\text { A2.2.1-D-Create video tutorials when students' } \\
\text { technology levels vary }\end{array}$ & $v^{*}$ & $*$ & & & & \\
\hline $\begin{array}{l}\text { M2.2.1 Provide links to videos about wikis and help } \\
\text { students understand wiki concepts and functions }\end{array}$ & & $v^{*}$ & & $v^{*}$ & $\mathrm{v} / \mathrm{s}$ & $v / s$ \\
\hline $\begin{array}{l}\text { M2.2.1.1 Skip videos if most students have been } \\
\text { trained to use wikis for collaboration }\end{array}$ & & & $v / s$ & & $\mathrm{v} / \mathrm{s}$ & $\mathrm{v} / \mathrm{s}$ \\
\hline $\begin{array}{l}\text { M2.2.2 Explicitly discuss students' concerns and } \\
\text { different mindsets of learning to support } \\
\text { collaborative learning on wikis }\end{array}$ & & & & $v^{*}$ & $v^{*}$ & $v^{*}$ \\
\hline $\begin{array}{l}\text { M2.2.2.1 Discuss different mindsets between } \\
\text { knowledge delivery and knowledge construction, } \\
\text { and how wikis are valued to support construction of } \\
\text { the learning experience. }\end{array}$ & & & & $v^{*}$ & $v^{*}$ & $v^{*}$ \\
\hline
\end{tabular}

Guidance for wiki-supported collaborative learning and community knowledge building for an entire class: Enhancing learning environments during the COVID19 pandemic. Chun-Yi Lin and Charles M. Reigeluth. 


\begin{tabular}{|c|c|c|c|c|c|c|}
\hline Method & V1.1 & V1.2 & C1 & $\mathrm{C} 2$ & V2.1 & V2.2 \\
\hline $\begin{array}{l}\text { M2.2.2.2 Help overcome the fear of posting in } \\
\text { public by re-thinking about wikis as a space for } \\
\text { sharing and facilitating learning process, rather } \\
\text { than turning in results for evaluation }\end{array}$ & & & $n^{*}$ & $v^{*}$ & $v^{*}$ & $v^{*}$ \\
\hline $\begin{array}{l}\text { M2.2.3 Explain expectations of learners on wikis } \\
\text { with examples about constructive and un- } \\
\text { constructive wiki behaviors }\end{array}$ & $v^{*}$ & $v^{*}$ & $v^{*}$ & v & $v$ & v \\
\hline M2.3 Help students develop wiki skills & & $v^{*}$ & v & v & $\mathrm{v}$ & v \\
\hline $\begin{array}{l}\text { M2.3.1 Give a tour of class wiki, including its } \\
\text { features }\end{array}$ & & $\mathrm{v}$ & $v^{*}$ & v & $v$ & v \\
\hline $\begin{array}{l}\text { M2.3.1.1 Offer one-on-one face-to-face tutorials to } \\
\text { students who are new to wikis or have technical } \\
\text { difficulties }\end{array}$ & & & v & v & $v$ & $\mathrm{v} / \mathrm{s}$ \\
\hline $\begin{array}{l}\text { M2.3.1.2 Encourage students to ask questions } \\
\text { about wikis which may also benefit others }\end{array}$ & & & v & v & $v$ & V \\
\hline $\begin{array}{l}\text { M2.3.1.3 Create a space for learning about wikis } \\
\text { (e.g., sharing self-paced tutorials, peer-coaching on } \\
\text { advanced features) }\end{array}$ & & & $n$ & $n$ & $v^{*}$ & v \\
\hline $\begin{array}{l}\text { M2.3.2 Explain wikis' limitations, anticipated } \\
\text { problems, and potential solutions }\end{array}$ & & $v^{*}$ & $\mathrm{v}$ & T & $v$ & v \\
\hline $\begin{array}{l}\text { M2.3.2.1 Explain the primary goal of wikis as to } \\
\text { support process-oriented knowledge building, } \\
\text { rather than product-oriented Web design }\end{array}$ & & & & $n$ & $v^{*}$ & v \\
\hline $\begin{array}{l}\text { M2.3.3 Create a sandbox and encourage } \\
\text { experiments }\end{array}$ & & $v^{*}$ & $v^{*}$ & $v^{*}$ & $v$ & v \\
\hline $\begin{array}{l}\text { M2.3.4 Assign tasks as soon as wiki skills are } \\
\text { introduced for practicing skills and discussing } \\
\text { concepts }\end{array}$ & & & v & $v^{*}$ & $v^{*}$ & v \\
\hline $\begin{array}{l}\text { M2.3.4.1 Help students create a wiki username, } \\
\text { password, and personal activity log page in class }\end{array}$ & & & & v & $v^{*}$ & v \\
\hline $\begin{array}{l}\text { M2.3.4.2 Require students to start with small tasks } \\
\text { on wikis (e.g., editing a personal page, adding } \\
\text { resources, then peer-editing) }\end{array}$ & & & v & v & $v^{*}$ & v \\
\hline M3 Foster a learning community & v & v & v & v & v & v \\
\hline $\begin{array}{l}\text { M3.1 Introduce knowledge co-construction on wikis } \\
\text { for community building }\end{array}$ & & v & $\mathrm{v}$ & v & $v$ & $v^{*}$ \\
\hline $\begin{array}{l}\text { M3.1.1 Initiate and discuss spaces for whole- } \\
\text { community collaboration }\end{array}$ & & $v^{*}$ & $v^{*}$ & v & $v$ & v \\
\hline $\begin{array}{l}\text { M3.1.1.1 Define wikis as learner-centered for co- } \\
\text { constructing learning experiences }\end{array}$ & & & & T & $v^{*}$ & v \\
\hline
\end{tabular}

Guidance for wiki-supported collaborative learning and community knowledge building for an entire class: Enhancing learning environments during the COVID19 pandemic. Chun-Yi Lin and Charles M. Reigeluth. 


\begin{tabular}{|c|c|c|c|c|c|c|}
\hline Method & V1.1 & V1.2 & C1 & C2 & V2.1 & V2.2 \\
\hline $\begin{array}{l}\text { M3.1.1.2 Discuss examples of varying ways (all } \\
\text { levels of contributions) to participate in community } \\
\text { building }\end{array}$ & & & $n$ & v & $v^{*}$ & v \\
\hline $\begin{array}{l}\text { M3.1.2 Structure activities in which individuals are } \\
\text { responsible for their own and peers' learning }\end{array}$ & $\mathrm{v}^{*}$ & $v^{*}$ & $v / p$ & v & v & v \\
\hline $\begin{array}{l}\text { M3.1.2.1 Require all students to participate in } \\
\text { community building (i.e., extrinsic motivation as in } \\
\text { M6.1) }\end{array}$ & & & $n$ & v & $v^{*}$ & v \\
\hline $\begin{array}{l}\text { M3.1.2.2 Discuss individuals' contributions to peer } \\
\text { coaching in community building (i.e., intrinsic } \\
\text { motivation, internalization) }\end{array}$ & & & n & $v^{*}$ & $v^{*}$ & $v^{*}$ \\
\hline $\begin{array}{l}\text { M3.2 Maximize participation and develop ownership } \\
\text { of work on wiki }\end{array}$ & $v^{*}$ & v & $v / p$ & v & v & v \\
\hline $\begin{array}{l}\text { M3.2.1 Encourage students to initiate or contribute } \\
\text { to a topic on wiki that extends in-class discussions }\end{array}$ & & $v^{*}$ & $v / p$ & v & v & $v^{*}$ \\
\hline $\begin{array}{l}\text { A33.2.1.1-D Guide participation by hosting a contest } \\
\text { (e.g., wiki banner design) }\end{array}$ & & & $\mathrm{v}^{*}$ & & * & \\
\hline $\begin{array}{l}\text { M3.2.1.1 Guide participation via weekly debriefings } \\
\text { and discussions (i.e., scaffolding from M3.1.2, } \\
\text { M3.2.1, to M3.2.2). Also see M5.1.2.1 }\end{array}$ & & & & $v^{*}$ & $v^{*}$ & $v^{*}$ \\
\hline $\begin{array}{l}\text { M3.2.2 Allow students to identify what needs to be } \\
\text { done on the wiki and take actions }\end{array}$ & & $v^{*}$ & $v / p$ & v & v & v \\
\hline $\begin{array}{l}\text { M3.2.3 Ensure students' active participation in all } \\
\text { stages of the collaborative writing processes, } \\
\text { including planning, composing, reviewing, and } \\
\text { correcting, (i.e., all levels of contributions) to } \\
\text { develop the sense of ownership }\end{array}$ & $v^{*}$ & $v^{*}$ & $v / p$ & v & v & v \\
\hline M4 Prepare for collaborative learning in small groups & v & v & v & v & v & v \\
\hline $\begin{array}{l}\text { M4.1 Decide to form collaborative learning groups, } \\
\text { cooperative project groups, or both. (See M4.2 for } \\
\text { cooperative project groups; M4.3 for collaborative } \\
\text { learning groups) }\end{array}$ & & & & $v^{*}$ & $v / s^{*}$ & $\mathrm{v} / \mathrm{s}$ \\
\hline M4.2 Help students form cooperative project groups & v & v & v & & v & $\mathrm{v}$ \\
\hline $\begin{array}{l}\text { M4.2.1 Allow students' to have self-organized } \\
\text { groups, which may be based on friendship or } \\
\text { academic interests }\end{array}$ & & $v^{*}$ & $V^{*}$ & & v & v \\
\hline $\begin{array}{l}\text { M4.2.2 Recommended group size varies depending } \\
\text { on the level of project complexity and instructional } \\
\text { needs (e.g., groups of two to three in a small class, } \\
\text { three to five in a large class) }\end{array}$ & & $v^{*}$ & v & & v & v \\
\hline
\end{tabular}

Guidance for wiki-supported collaborative learning and community knowledge building for an entire class: Enhancing learning environments during the COVID19 pandemic. Chun-Yi Lin and Charles M. Reigeluth. 
RED. Revista de Educación a Distancia. Núm. 65, Vol. 21. Artíc. 1, 08-01-2021

DOI: http://dx.doi.org/10.6018/red.447401

\begin{tabular}{|c|c|c|c|c|c|c|}
\hline Method & V1.1 & V1.2 & C1 & $\mathrm{C2}$ & V2.1 & V2.2 \\
\hline $\begin{array}{l}\text { M4.2.3 Encourage students to organize groups on } \\
\text { wiki (list or find a group on a group listing page) }\end{array}$ & & & $v^{*}$ & & $v^{*}$ & v \\
\hline A4.2.1-D Start with pairs & $v^{*}$ & * & & & & \\
\hline $\begin{array}{l}\text { M4.2.2-D Observe student characteristics during } \\
\text { interaction }\end{array}$ & $v^{*}$ & * & & & & \\
\hline $\begin{array}{l}\text { A44.2.3-DAssign heterogeneous groups based on } \\
\text { student characteristics or based on their academic } \\
\text { interests first }\end{array}$ & $v^{*}$ & * & * & & & \\
\hline A44.2.4-DForm groups of four to-six & $v^{*}$ & * & & & & \\
\hline M4.3 Help students form collaborative learning groups & & & & $v^{*}$ & $v^{*}$ & v \\
\hline $\begin{array}{l}\text { M4.3.1 Assign purposive groups (e.g., randomly or } \\
\text { by shared academic interests) }\end{array}$ & & & & $v^{*}$ & v & v \\
\hline $\begin{array}{l}\text { M4.3.2 Recommended group size varies depending } \\
\text { on activities }\end{array}$ & & & & & v & v \\
\hline $\begin{array}{l}\text { M4.3.3 Assign and facilitate collaborative learning } \\
\text { activities (e.g., taking turns to share work and } \\
\text { receive feedback in person or on wiki) }\end{array}$ & & & & $v^{*}$ & v & v \\
\hline M4.4 Prepare students with group skills & v & v & v & v & v & v \\
\hline $\begin{array}{l}\text { M4.4.1 Discuss advantages and drawbacks of } \\
\text { working in groups }\end{array}$ & & $v^{*}$ & v & & v & v \\
\hline $\begin{array}{l}\text { M4.4.2 Give opportunities for face-to-face } \\
\text { interaction to build trust }\end{array}$ & $v^{*}$ & $v$ & $v^{*}$ & v & v & $\mathrm{v} / \mathrm{s}$ \\
\hline $\begin{array}{l}\text { M4.4.3 Plan effective communication and } \\
\text { interaction }\end{array}$ & $v^{*}$ & $v$ & $v^{*}$ & v & v & v \\
\hline $\begin{array}{l}\text { M5 Scaffold collaborative learning and cognitive } \\
\text { development }\end{array}$ & v & $v$ & v & v & v & v \\
\hline M5.1 Facilitate the collaborative learning process & v & v & v & v & v & v \\
\hline $\begin{array}{l}\text { M5.1.1 Observe collaborative learning behaviors } \\
\text { (i.e., interaction and edits), and pay close attention } \\
\text { to student progress and needs. Subscribe change } \\
\text { notifications to monitor activities on wiki. }\end{array}$ & v & $v^{*}$ & v & v & v & v \\
\hline $\begin{array}{l}\text { M5.1.2 Provide timely feedback to facilitate } \\
\text { cognitive and meta-cognitive development }\end{array}$ & $v^{*}$ & $v^{*}$ & v & v & v & v \\
\hline $\begin{array}{l}\text { M5.1.2.1 In weekly debriefings and discussions, } \\
\text { share observations, foster reflection on progress, } \\
\text { strategies, and conflicts, and discuss possible } \\
\text { improvements }\end{array}$ & & & v & $v^{*}$ & $v^{*}$ & v \\
\hline M5.1.2.2 Provide customized feedback face-to-face & & & $\mathrm{v}$ & v & v & v \\
\hline $\begin{array}{l}\text { M5.1.2.3 Provide customized feedback online using } \\
\text { wikis or messages }\end{array}$ & & & $v^{*}$ & v & v & v \\
\hline
\end{tabular}

Guidance for wiki-supported collaborative learning and community knowledge building for an entire class: Enhancing learning environments during the COVID19 pandemic. Chun-Yi Lin and Charles M. Reigeluth. 


\begin{tabular}{|c|c|c|c|c|c|c|}
\hline Method & V1.1 & V1.2 & C1 & $\mathrm{C} 2$ & V2.1 & V2.2 \\
\hline $\begin{array}{l}\text { M5.1.3 Encourage groups to pause, review, and } \\
\text { discuss their operations and progress frequently or } \\
\text { in each project stage }\end{array}$ & $v^{*}$ & v & v & v & v & v \\
\hline $\begin{array}{l}\text { M5.1.3.1 Help groups recognize and resolve } \\
\text { conflicts independently (e.g., remind to } \\
\text { communicate within groups before reporting to } \\
\text { instructors) }\end{array}$ & $v^{*}$ & $v^{*}$ & $v^{*}$ & v & $v$ & v \\
\hline $\begin{array}{l}\text { M5.1.4 Provide a sense of success, reward through } \\
\text { recognition, and opportunities for vicarious learning } \\
\text { by making group projects available on the wiki and } \\
\text { giving all students opportunities to present their } \\
\text { projects }\end{array}$ & $v^{*}$ & $v^{*}$ & v & v & v & v \\
\hline M5.2 Promote critical and creative thinking & $\mathrm{v}$ & v & v & v & v & v \\
\hline $\begin{array}{l}\text { M5.2.1 Advocate creative thinking by offering } \\
\text { choices (e.g., topics, strategies, and media for } \\
\text { presentations) and scaffolding decision-making } \\
\text { processes }\end{array}$ & v & $v^{*}$ & $v^{*}$ & $v^{*}$ & v & v \\
\hline $\begin{array}{l}\text { M5.2.2 Advocate critical thinking in projects, } \\
\text { especially through peer-coaching and peer } \\
\text { feedback processes }\end{array}$ & $v^{*}$ & v & $v^{*}$ & $v^{*}$ & v & v \\
\hline $\begin{array}{l}\text { M5.2.2.1 Emphasize value of collaboration, peer- } \\
\text { coaching, and collaborative relationships in a new } \\
\text { model of learning during weekly discussions to } \\
\text { eliminate any resistance from an old mindset }\end{array}$ & & & n & $v^{*}$ & $v^{*}$ & $v^{*}$ \\
\hline $\begin{array}{l}\text { M5.2.2.2 Discuss and post guidelines for writing } \\
\text { effective peer feedback }\end{array}$ & & v & $v / p^{*}$ & $v^{*}$ & $v^{*}$ & v \\
\hline $\begin{array}{l}\text { M5.2.2.3 Allow students to select projects to which } \\
\text { they will give feedback }\end{array}$ & & $v^{*}$ & v & v & v & v \\
\hline $\begin{array}{l}\text { M5.2.3 Provide formal and informal feedback to } \\
\text { encourage or challenge students }\end{array}$ & $v^{*}$ & v & $v^{*}$ & v & v & v \\
\hline $\begin{array}{l}\text { M5.2.3.1 Provide informal feedback through } \\
\text { messages and face-to-face interaction (i.e., } \\
\text { M5.1.2.2, M5.1.2.3) }\end{array}$ & & & $v^{*}$ & v & v & v \\
\hline $\begin{array}{l}\text { M5.2.3.2 Provide formal feedback after each } \\
\text { project or project stage, mostly in written format } \\
\text { (i.e., M6.2.1) }\end{array}$ & & & v & v & v & v \\
\hline M5.3 Advocate self-directed learning & & $\mathrm{v}$ & v & v & v & v \\
\hline $\begin{array}{l}\text { M5.3.1 Require students to keep personal activity } \\
\text { logs to foster self-monitoring and self-reflection on } \\
\text { learning progress. }\end{array}$ & & $v^{*}$ & & $v^{*}$ & $v^{*}$ & v \\
\hline
\end{tabular}

Guidance for wiki-supported collaborative learning and community knowledge building for an entire class: Enhancing learning environments during the COVID19 pandemic. Chun-Yi Lin and Charles M. Reigeluth. 


\begin{tabular}{|c|c|c|c|c|c|c|}
\hline Method & V1.1 & V1.2 & C1 & $\mathrm{C} 2$ & V2.1 & V2.2 \\
\hline $\begin{array}{l}\text { M5.3.1.1 Require students to document, annotate, } \\
\text { and link to contributions (e.g., projects, edits, peer } \\
\text { feedback posts). Encourage reflection. }\end{array}$ & & & & $v^{*}$ & $v^{*}$ & $v^{*}$ \\
\hline $\begin{array}{l}\text { M5.3.2 Optional: Require students to create } \\
\text { personal wikis as portfolios to document their } \\
\text { work, if appropriate. }\end{array}$ & & & v & & $s^{*}$ & $s$ \\
\hline M6 Assess learning outcomes with formative feedback & $\mathrm{v}$ & $\mathrm{v}$ & v & v & $\mathrm{v}$ & $\mathrm{v}$ \\
\hline $\begin{array}{l}\text { M6.1 Before assessments, provide clear guidelines } \\
\text { (i.e., expectations, extrinsic motivators) }\end{array}$ & $v^{*}$ & $v$ & $v^{*}$ & $v^{*}$ & v & v \\
\hline M6.1.1 Offer no rubrics, to encourage creativity & & $v^{*}$ & $v^{*}$ & v & v & v \\
\hline $\begin{array}{l}\text { M6.1.2 Remind students what will be assessed } \\
\text { during projects }\end{array}$ & & & & v & v & V \\
\hline $\begin{array}{l}\text { M6.2 Assess individual projects, quality of group work, } \\
\text { and individual contributions to group work }\end{array}$ & $v^{*}$ & 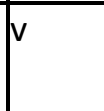 & v & V & v & v \\
\hline $\begin{array}{l}\text { M6.2.1 Assess projects at multiple project stages } \\
\text { and offer informative feedback to proceed }\end{array}$ & & & v & v & $v^{*}$ & v \\
\hline $\begin{array}{l}\text { M6.2.2 Assess contributions to community building } \\
\text { and peer-coaching using the "floating grade" } \\
\text { technique }\end{array}$ & & & $n$ & $v^{*}$ & s* & $\mathrm{v}^{*}$ \\
\hline $\begin{array}{l}\text { M6.2.2.1 Evaluate activity logs at multiple points in } \\
\text { time, and offer informative feedback to improve }\end{array}$ & & & $\mathrm{v} / \mathrm{p}$ & $v^{*}$ & $v^{*}$ & $v^{*}$ \\
\hline $\begin{array}{l}\text { M6.2.3 Optional: Require peer evaluation of activity } \\
\text { logs }\end{array}$ & & & $n$ & v & $\mathrm{s}^{*}$ & $v^{*}$ \\
\hline
\end{tabular}

\section{Commentary on Changed Methods}

(Note that Italics in this section indicate wording of the method in Table 1.)

To support students' project-based learning in small groups, instructors may establish multiple project stages or milestones for complex tasks (M1.2.2 - sub-method added). The purpose is to help students manage projects, and encourage them to pause, review, and discuss group operation and progress through participating in discussions and receiving feedback from instructors and peers at several stages to improve their projects.

On wikis, include diverse examples of community building tasks on wiki (M1.3.2 - submethod added): When preparing the class wiki site before class begins, instructors should consider providing some structure on class wikis, including written guidelines and examples of community building. By doing so, instructors increase students' opportunities to review the guidelines while students are contributing to class wikis, and to expand their strategies to participate. Additionally, written guidelines help students who have missed classes to catch up. For example, Expert A stated: "If it's just at the beginning, say 'Yeah, we're going to do it this way.' Inevitably, people who screw this up [fail to understand or contribute to the wiki]

Guidance for wiki-supported collaborative learning and community knowledge building for an entire class: Enhancing learning environments during the COVID19 pandemic. Chun-Yi Lin and Charles M. Reigeluth. 
are never there. You couldn't reach them, but at least you cover yourself by saying, 'We've talked about this [with the written guidelines posted on the wiki]!"”

For small classes, consider building a large community on wiki by collaboration with multiple sections (M1.4 - based on the situation; situationality added). Instructors who coordinate a course with multiple small sections may consider using a wiki to encourage collaboration among students from multiple sections. The reason is that, as demonstrated by evidence in Case Two and later agreed upon by both experts, students are more inspired and motivated in the learning process when there are more edits and interactions on wikis from a larger number of students with different backgrounds, skills, knowledge, goals, and interests. Expert B described this method during the focus-group interview for V2.1:

I mean I like it for multiple sections because I think there's a critical mass that makes it very interesting. You get more people. You have more activity. It's like a bigger community, so rather than having a, you know, a tiny village of 25 people, now you have a city of whatever -60 people or 65 were in mine. So I think it uses more activity. I think there's more interaction. I think there's more potential.

In addition to "turning small villages into a big city" offering a rich learning experience, using one wiki for multiple small sections may benefit instructors. By implementing this method, the openness of the wiki creates opportunities for instructors to reflect on and communicate the curriculum, project design, and student progress, as well as to promote coordination and collaboration with other instructors.

Note on M1.4 for v2.2: During pandemic situations, almost all large-gathering events are banned to reduce the chances of viral infection. Therefore, some large classes are moved online, while some are divided into small sections. In either case, it would be beneficial to have a class wiki space for students in a large class to collaborate on projects in small groups, as evidenced by the previous success in Case 1 (Lin \& Reigeluth, 2016) or for students in a small class to collaborate with students in other sections on community knowledge building, as evidenced by the previous success in Case 2 (Lin \& Reigeluth, 2019).

Explicitly discuss students' concerns and different mindsets of learning to support collaborative learning on wikis (M2.2.2 - sub-method added): The discussion includes different mindsets between knowledge delivery and knowledge construction, and how wikis are valued to support construction of learning experience (M2.2.2.1 - sub-method added). By leading an in-depth discussion about the new mindset of learning (i.e., collaborative, learnercentered, not the traditional teacher-centered mindset), instructors help students establish the importance of participating in community building on class wikis for their own learning. Similarly, instructors may help students overcome the fear of posting in public by re-thinking about wikis as a space for sharing and facilitating the learning process through collective efforts, rather than turning in results for evaluation (M2.2.2.2 - sub-method added).

Note on M2.2.2 for v2.2: To many instructors, recording lectures and making them available to all students online seems to have been the major task in the beginning of the

Guidance for wiki-supported collaborative learning and community knowledge building for an entire class: Enhancing learning environments during the COVID19 pandemic. Chun-Yi Lin and Charles M. Reigeluth. 
pandemic. However, we think that, in the long term, knowledge delivery itself is insufficient to meet today's learning demands given that students learn better by doing and the world needs collaborative problem-finders and problem-solvers, who can ask questions and be open to different ideas, and evaluate and apply what they have learned effectively and meaningfully in new contexts. Meanwhile, individuals need to learn to become active participants in the process, to become effective life-long learners. Thus, knowledge construction is desired, and can be practiced and improved through reflection during wiki collaboration.

Two sub-methods to help students develop their wiki skills were identified from interviews with students. Instructors may create a space for learning about wikis with peers, e.g., sharing self-paced tutorials and peer-coaching on advanced features (M2.3.1.3 - submethod added). Several students from both cases mentioned the desire to have or collaborate on a page for learning advanced wiki features; therefore, instructors may consider creating such a space and encouraging peer learning. While some students liked to learn more about wiki features, some students were frustrated with too user-friendly wiki features ("for dummies," as they called it), which are not HTML or CSS compatible. However, according to Expert B, a wiki "is not meant for that. It's meant for quick getting things down, documenting and sharing, you know, all those kinds of things. It's not meant for final." Therefore, it is important to explain the primary goal of wikis as to support process-oriented knowledge building, rather than product-oriented Web design (M2.3.2.1 - sub-method added). As wikis primarily promote knowledge building, not the aesthetic beauty of sites, the tool currently does not support users in full customization of site appearance through a variety of Web design languages, perhaps to minimize confusion and maximize participation from all users.

The following new sub-methods were added to reinforce both students' wiki skills and wiki concepts. Expert B shared that an important lesson he learned was to assign tasks as soon as wiki skills are introduced for practicing skills and discussing concepts (M2.3.4 - submethod added). An example of such a task was to help students create a wiki username and password and a personal activity log in class (M2.3.4.1 - sub-method added):

B: On the first day, they each created a user name, and then I made them come up one by one to me, and I added them to the index ( $A$ : Oh, okay.) just so that I knew who they were, and I typed it in, and I showed them. 'Okay, so here's your first kind of page'.... It helped me because I got to know them on the first day. (A: Yeah. That's it. That's great!) Yeah. Face-to-face. Like, 'What's your name? How do you spell that, blah blah blah. How you doing? And uh ... what's your user name? And here's your first page, go for it now.'

Also, both experts required students to start with small tasks on wikis, e.g., editing a personal page, adding resources, then peer-editing (M2.3.4.2 - sub-method added). Expert B learned to have students practice community building:

Guidance for wiki-supported collaborative learning and community knowledge building for an entire class: Enhancing learning environments during the COVID19 pandemic. Chun-Yi Lin and Charles M. Reigeluth. 
Although they (students) feel that there's little technology barrier, it's important to get them to do stuff right away, right? And I think I learned this year finally, after many years of doing this, that I would give them something to do in the first day and not just put their name up and start their activity log. Maybe say, 'You have to go find something that relates to this or course material and put it up there ....'

He continued the conversation, explaining how to assign collaborative learning groups to practice editing peers' work.

To introduce collaborative knowledge construction for community building on class wikis, instructors need to define wikis as learner-centered for co-constructing the learning experience (M3.1.1.1 - sub-method added). Emphasizing that a class wiki is a learnercentered space for constructing knowledge, rather than a teacher-centered space for delivering content, communicates the expectation of students' taking leadership in community building. Additionally, discussing examples of varying ways (all levels of contributions) to participate in community building (M3.1.1.2 - sub-method added) helps students better understand community building. Instructors may encourage students to come up with new examples and expand the list on class wikis.

As part of designing and preparing for community building, it is important for instructors to structure activities in which individuals are responsible for their own and their peers' learning (M3.1.2). First, based on the evidence presented in the two cases and the discussion in the second focus-group interview, requiring all students to participate in community building (M3.1.2.1 - sub-method added) offers extrinsic motivation; including it in assessment affects student participation in community building and hold individuals accountable. Second, to promote self-regulated learning and increase students' enjoyment and engagement in community building, instructors should help students understand that their participation not only benefits their own learning, but also facilitates their peers' learning. Therefore, instructors should discuss individuals' contributions to peer coaching in community building by offering diverse perspectives and strengths (M3.1.2.2 - sub-method added). For instance, school assignments could be transformed into opportunities for peer teaching-and-learning on the wiki.

In addition to the above sub-methods for maximizing participation in community building, Expert A tried a new idea - to guide participation by hosting a competition, i.e., wiki banner design contest, but he later indicated that, "Unfortunately, it didn't work" (M3.2.1.1D sub-method removed). The experts discussed potential factors that influence the success of guiding activities, including the nature of the course and students' interests. Although the banner contest guiding activity was not successful, the experts found that weekly debriefings and discussions encouraged participation (M3.2.1.1 - sub-method added, also see M5.1.2.1) through recognizing what students have done on wiki previously and reflecting on what students have learned. This is because the experts scaffolded the process from cognitively understanding participation with concrete examples (M3.1.2), through instructors' feedback

Guidance for wiki-supported collaborative learning and community knowledge building for an entire class: Enhancing learning environments during the COVID19 pandemic. Chun-Yi Lin and Charles M. Reigeluth. 
on students' participation (M3.2.1), to empowering students' decision-making on what needs to be done and taking actions (M3.2.2).

For V2.2, we would like to highlight the importance and feasibility of M3.1.2.2, M3.2.1, M3.2.1.1, especially weekly discussions on students' various contributions on class wikis to connect with each other, and to engage peers in learning. If a large class is completely moved online or divided into small sections due to COVID-19, instructors can not only post their lectures to guide learning, but to offer weekly debriefings about what has happened in the community, such as what interesting and valuable conversations are going on in the class wiki this week. In this way, learning is less isolated but more supported and enriched by student collaboration with their peers. We found in Case 2 that students shared new knowledge or skills acquired from independent inquiry, related to, but beyond, what is taught by the instructor. Then, other students found the content interesting, so they updated the content to make it better. Students were able to see other students' work-in-progress, ask questions, help others, or receive feedback, so they found learning this way engaging.

In the method for scaffolding learning in small groups, several sub-methods were added: Decide to form collaborative learning groups or cooperative project groups (M4.1 situationality added). The major difference is that students in a cooperative project group work interdependently for a considerable amount of time to achieve a shared goal (such as a project), whereas students in a collaborative learning group help each other to achieve individual learning goals as long as needed. The sub-methods for scaffolding collaborative learning groups were added as $\mathbf{M}$ 4.3.1, M4.3.2, and M4.3.3. For preparing cooperative learning groups, instructors may encourage students to organize groups on the wiki by listing or finding a group on a group listing page (M4.2.3 - sub-method added).

To scaffold collaborative learning, especially during community building on class wikis, one of the key sub-methods is weekly or frequent debriefings with the class: In weekly debriefings and discussions, instructors share observations, foster reflection on progress, strategies, and conflicts, and discuss possible improvements with students (M5.1.2.1 - submethod added):

B: You know, I think, as an instructor, you really have to be looking at it regularly (A: Yeah.) to sort of get a sense of what's going on. ... I did, like, point out a couple over the week that I saw had done something quite valuable, and I would say, "Oh, you know, so and so did this."

A: Yeah. That's handy 'cause people like having some sort of individual recognition for what they've done type of thing.

During weekly discussions with the whole class, instructors not only share observations with students but also foster community building by helping students reflect on their learning in the process, providing a sense of success, rewards through recognition, and opportunities for vicarious learning (M5.1.4).

In addition, instructors should provide timely feedback to individuals or groups as

Guidance for wiki-supported collaborative learning and community knowledge building for an entire class: Enhancing learning environments during the COVID19 pandemic. Chun-Yi Lin and Charles M. Reigeluth. 
needed to scaffold creative and critical thinking. Instructors may meet with students face-toface to offer guidance and customized feedback (M5.1.2.2 - sub-method added) and provide feedback by using wikis or messages (M5.1.2.3 - sub-method added). The goal is to offer students timely feedback for making adjustments in learning strategies, as well as to reflect on the effectiveness of instruction and make possible improvements.

To promote higher-order thinking through peer feedback, two sub-methods were added: First, instructors can discuss and post guidelines for writing effective peer feedback (M5.2.2.2 - sub-method added), so that students may refer to the guidelines when they create feedback. The other sub-method, a potential solution to the problem that some students resisted giving their best advice during implementation, is to emphasize the values of collaboration, peer-coaching, and collaborative relationships in a new model of learning during weekly discussions to eliminate the resistance from an old mindset (M5.2.2.1 - submethod added). In traditional classrooms, students may view their peers as competitors due to norm-referenced assessments (i.e., students are evaluated by comparing with peers); therefore, some students who retain the old mindset may have resistance to helping their peers. It may be wise to use criterion-referenced assessment (i.e., students are evaluated for their competence in meeting criteria) and help students see how they may benefit from helping each other to achieve learning goals, thinking of their contributions as gifts to peers and establishing collaborative relationships with peers. We think that M5.2.2.1 is also crucial in the pandemic (v2.2). By highlighting the value of collaboration, peer-coaching, and collaborative relationships, students will understand why to practice active participation in collective knowledge building and collaborative problem-solving for work and civic engagement.

As for promoting self-directed learning, requiring students to keep personal activity logs to foster self-monitoring and self-reflection on learning progress (M5.3.1) is key and was successfully implemented in small classes. Students become self-directed learners as they document, annotate, and link to contributions for projects, edits, and peer feedback posts (M5.3.1.1 - sub-method added). In the process, they observe their own contributions to the community, become aware of knowledge gaps, and offer instructors a way to understand their learning as "a roadmap," as Expert B called the activity log. The other option to support self-directed learning beyond the class is to encourage students to create portfolios on wikis: Optional: Require students to create personal wikis as portfolios to document their work (M5.3.2 - sub-method added, based on the situation). If time permits and the program calls for student portfolios, instructors may have students create portfolios on wikis.

A: Their personal Wiki space, you know, they're becoming interesting portfolios. I mean they're documenting two or three years of their work in one space. (B: "Yeah. Interesting.") So it's a different way.... I think it makes sense because it forces people to not only represent what they've done, but what they've done becomes a reflective learning opportunity in the end.

Guidance for wiki-supported collaborative learning and community knowledge building for an entire class: Enhancing learning environments during the COVID19 pandemic. Chun-Yi Lin and Charles M. Reigeluth. 
In assessment (M6), several sub-methods were added to address the need for individual accountability in community building and effective scaffolding in cognitive development. For example, project stages are established (M1.2.2) and assessing projects at multiple project stages and offering informative feedback to proceed (M6.2.1 - sub-method added) helps students improve as they proceed. As to assessment of individuals' contributions to community building (including peer feedback and editing for knowledge coconstruction on class wikis) is crucial, given that it plays an important role in holding students accountable and fostering community building. The assessment design was described as assessing contributions to community building and peer coaching using the "floating grade" technique (M6.2.2 - sub-method added) and evaluating activity logs at multiple points in time, and offering informative feedback to improve (M6.2.2.1 - sub-method added) to address the challenges in assessment.

Because of the large number of edits and interactions made by all students, students' self-organization is desired to help instructors understand individuals' work in the peer coaching process: Having students generate personal activity logs (as discussed in M5.3.1), with short descriptions and links to their contributions, not only promotes self-directed learning, but also increases efficiency in locating and evaluating contributions. Expert B said, "So the activity log was one way of getting them to actually map it out themselves. That was helpful." Although activity logs provide "maps" to understand contributions, for instructors of large classes (especially those without assistants), constantly monitoring and evaluating the accuracy of activity logs can still be challenging (a concern addressed by Expert A). However, perhaps peer evaluation on students' activity logs (M6.2.3 - situationality added) should be considered if students are not overwhelmed by too many tasks, and if vicarious learning is important to the course. Given the nature of class wikis as an open learning environment, students may be another source for triangulating instructors' evaluations and enhancing the accuracy of activity logs.

For v2.2, we recommend students keep activity logs on class wikis as their "roadmaps" of learning (M5.3.1), instructors offering floating grades to encourage improvements (M6.2.2.1), and peers offering feedback on activity logs to increase the opportunity for vicarious learning and peer coaching (M6.2.3). The reason is that these methods make one's learning process "visible" to others on the wiki; therefore, members of the class community can learn from each other or support each other. For example, students and instructors would be able to know when, how, and what independent inquiry and participation in community building were taking place for each student to reach deep understandings and good project results.

\footnotetext{
2 A floating grade shows students' effort to participate in community building and peer learning from the first day until the time of assessment. Assessments should be conducted at several different times, so that a student grade may change over time to encourage improvement and hold attention.
}

Guidance for wiki-supported collaborative learning and community knowledge building for an entire class: Enhancing learning environments during the COVID19 pandemic. Chun-Yi Lin and Charles M. Reigeluth. 


\section{Discussion and Conclusions}

In the findings section, we presented an instructional theory for using a class wiki for collaboration in small groups, as well as for community knowledge building in an entire class. Here, we discuss how class wikis in this instructional theory may enhance learning by supporting the four integrated perspectives on learning environments (i.e., learner-centered, knowledge-centered, community-centered, and assessment-centered, described in the book How people learn: Brain, Mind, Experience, and School [National Research Council, 2000]). In addition, we conclude this paper with a summary table about the instructional methods and experts' heuristics in response to the practical challenges in previous research.

\section{Learner-Centered Environment}

On a class wiki co-created by students, instructors become aware of the knowledge, skills, and ideas that students bring to class when the instructors encourage students to identify what needs to be done and take actions for small group collaboration and community building. Students should also be encouraged to document their personal activity logs and to reflect, which together make their thinking visible for formative evaluation, self-directed learning and peer learning. Meanwhile, instructors need to be aware that students' existing mindsets of learning (e.g., typically competitive and product- or performance-oriented) may conflict with the new mindset of learning (e.g., collaborative and process- or learningoriented) introduced through wiki collaboration and hinder participation. Thus, it is essential to explicitly help students understand that the purpose of class wikis is to foster a culture of sharing through their active participation in working together and learning from each other, which is also valuable in most workplaces.

\section{Knowledge-centered environment and community-centered environment}

A class wiki is also a knowledge-centered environment to help students acquire new knowledge and skills. What is unique in this instructional theory is that students, not instructors, are expected to take the lead to create knowledge that has "high value" to other students, and to organize knowledge on a class wiki. In other words, students may need to conduct independent inquiry relevant to weekly lectures or to their projects, then judge what knowledge may be helpful to contribute to other people's learning. Students are motivated to contribute to knowledge building when they know what they do impacts the community (i.e., peers in the class).

\section{Assessment-centered environment}

In this instructional theory, a class wiki can provide unique opportunities for givingand-taking formative feedback and revisions. Because students' thinking and working process becomes visible on the wiki, not only can instructors offer feedback at multiple stages, but

Guidance for wiki-supported collaborative learning and community knowledge building for an entire class: Enhancing learning environments during the COVID19 pandemic. Chun-Yi Lin and Charles M. Reigeluth. 
students can interact by sending messages on activity log pages and can collaborate on knowledge building by initiating, or building on, others' contributions. Note that, even though the projects and contributions to community building are assessed based on course objectives, student learning is not constrained by a pre-defined set of knowledge, but is supported in this peer co-constructed learning environment with rich inspirations, connections, and collaborations.

\section{Conclusion and Future Research}

To respond to the real-world challenges during the wiki collaboration process in higher education, we developed an instructional theory with expert practitioners based on two implementations, including class observations, content analysis, and interviews. Table 2 summarizes the proposed solutions and the corresponding design principles. We find this theory has several implications for emergency remote teaching during a pandemic, including to enrich the learning environments. However, future research to study the use of the theory in such situations is needed to improve the instructional methods and increase the generalizability.

Table 2

The Contributions to Practical Challenges of Using Wikis in Classrooms

\begin{tabular}{|c|c|c|}
\hline $\begin{array}{l}\text { Real-world } \\
\text { challenges }\end{array}$ & Proposed solutions (in methods) & $\begin{array}{l}\text { Design principles (in heuristics and } \\
\text { theoretical foundations) }\end{array}$ \\
\hline $\begin{array}{l}\text { Lack of } \\
\text { incentives: } \\
\text { Lack of } \\
\text { motivation }\end{array}$ & $\begin{array}{l}\text { Provide extrinsic motivators and } \\
\text { guide self-regulated learning: } \\
\text { Structure activities in which } \\
\text { individuals are responsible for their } \\
\text { own and peers' learning M3.1.2. } \\
\text { Support with communication of } \\
\text { expectations and assessment design } \\
\text { M6.1, M6.2. } \\
\text { Make wiki projects interesting by } \\
\text { fostering activity and interaction in a } \\
\text { large community M1.4. } \\
\text { Help students understand the value of } \\
\text { wiki projects M2.1, M2.2, M3.1. } \\
\text { Help students reflect on their } \\
\text { experience, receive feedback, } \\
\text { increase confidence, and adjust } \\
\text { strategies M5.1. }\end{array}$ & $\begin{array}{l}\text { Experts identified assessment design as } \\
\text { an important factor to maximize } \\
\text { participation. Cooperative learning } \\
\text { literature also supports the design to } \\
\text { address individual accountability. } \\
\text { Experts explained how a large } \\
\text { community makes class wikis engaging, } \\
\text { which may increase intrinsic } \\
\text { motivation based on self- } \\
\text { determination theory. } \\
\text { Experts performed weekly discussions } \\
\text { with students in light of guiding } \\
\text { participation, through vicarious } \\
\text { learning, self-reflection, etc., supported } \\
\text { by self-efficacy and social learning } \\
\text { theories. }\end{array}$ \\
\hline
\end{tabular}

Guidance for wiki-supported collaborative learning and community knowledge building for an entire class: Enhancing learning environments during the COVID19 pandemic. Chun-Yi Lin and Charles M. Reigeluth. 


\begin{tabular}{|c|c|c|}
\hline & $\begin{array}{l}\text { Encourage students to independently } \\
\text { identify what needs to be done and } \\
\text { take action M3.2. }\end{array}$ & $\begin{array}{l}\text { Experts explained the importance of wiki } \\
\text { projects to learning and preparing for } \\
\text { future careers, and helped learners } \\
\text { internalize and integrate values. As } \\
\text { students perceive autonomy (ability to } \\
\text { decide what to contribute) on wiki } \\
\text { projects, they become self-directed. } \\
\text { This is supported by self-determination } \\
\text { theory. }\end{array}$ \\
\hline $\begin{array}{l}\text { Lack of } \\
\text { ownership: } \\
\text { Hesitation to } \\
\text { participate } \\
\text { (publicity) } \\
\text { Refusal to edit } \\
\text { others' work } \\
\text { (authority) }\end{array}$ & $\begin{array}{l}\text { Help students shift focus to "process" } \\
\text { rather than "product" (understand } \\
\text { that wiki is a space to facilitate } \\
\text { learning-in-progress) M2.3.2.1 } \\
\text { Help students reflect on the benefits } \\
\text { of peer-coaching on wikis M5.2.2.1 } \\
\text { and understand that revision is a } \\
\text { natural part of learning (and wiki) } \\
\text { M2.2, M5.1 } \\
\text { Provide and post guidelines for } \\
\text { community building and peer } \\
\text { feedback on wikis to foster mutual } \\
\text { understanding M1.3.2, M5.2.2.2 } \\
\text { Encourage all levels of contributions } \\
\text { to community building M3.2.3 }\end{array}$ & $\begin{array}{l}\text { The two experts explained how students } \\
\text { could over-focus on product, } \\
\text { undermining the importance of } \\
\text { thinking in the process, which } \\
\text { corresponds with the theory of writing } \\
\text { with respect to fostering higher-order } \\
\text { thinking in writing. } \\
\text { The experts demonstrated and explained } \\
\text { scaffolding to address conflicting } \\
\text { mindsets (old and new models of } \\
\text { learning) and help students adopt } \\
\text { collaborative relationships in learning } \\
\text { when introducing wiki concepts and } \\
\text { hosting weekly discussions. } \\
\text { Literature suggests requiring students to } \\
\text { participate throughout the process to } \\
\text { develop collective ownership of wiki } \\
\text { work - supported by collaborative } \\
\text { writing theory. }\end{array}$ \\
\hline $\begin{array}{l}\text { Group } \\
\text { dynamics: } \\
\text { Lack of trust } \\
\text { Need to } \\
\text { develop a } \\
\text { give-and-take } \\
\text { culture }\end{array}$ & $\begin{array}{l}\text { Allow students to form self-organized } \\
\text { groups for cooperative project } \\
\text { groups M4.2.1 } \\
\text { Prepare students' small-group } \\
\text { collaboration skills, such as } \\
\text { discussions about advantages and } \\
\text { drawbacks of working in groups, } \\
\text { responsibility to communicate with } \\
\text { all members when interpersonal } \\
\text { conflicts occur in the group, and } \\
\text { planning effective communication } \\
\text { M4.4. }\end{array}$ & $\begin{array}{l}\text { Experts identified the challenges of } \\
\text { instructor-formed groups in small- } \\
\text { group project-based learning } \\
\text { (contradicts suggestions from the } \\
\text { cooperative learning literature) as lack } \\
\text { of trust, which leads to ineffective } \\
\text { group processing and interpersonal } \\
\text { conflicts. Experts also explained how } \\
\text { self-organized groups with effective } \\
\text { communication eliminate the problem } \\
\text { and improve learning. } \\
\text { Similar to the previous challenge, due to } \\
\text { conflicting learning models, to help }\end{array}$ \\
\hline
\end{tabular}

Guidance for wiki-supported collaborative learning and community knowledge building for an entire class: Enhancing learning environments during the COVID19 pandemic. Chun-Yi Lin and Charles M. Reigeluth. 


\begin{tabular}{|c|c|c|}
\hline & $\begin{array}{l}\text { Use collaborative learning groups } \\
\text { M4.3 to practice and demonstrate } \\
\text { peer-coaching in a small group } \\
\text { In weekly discussions, reinforce the } \\
\text { importance and value of peer- } \\
\text { coaching to help internalize such } \\
\text { value and belief M5.2. }\end{array}$ & $\begin{array}{l}\text { students develop a give-and-take } \\
\text { culture, weekly discussions were } \\
\text { suggested to foster reflection, mutual } \\
\text { understanding (as no one wants to be } \\
\text { perceived as critical when editing } \\
\text { others' work), and internalization of } \\
\text { beliefs. }\end{array}$ \\
\hline $\begin{array}{l}\text { Assessment: } \\
\text { Time- } \\
\text { consuming } \\
\text { Feedback had } \\
\text { minor effect }\end{array}$ & $\begin{array}{l}\text { Require student self-organized } \\
\text { personal activity logs to promote } \\
\text { self-monitoring and self-reflection, } \\
\text { and to aid the process of evaluation } \\
\text { of individuals' contributions to } \\
\text { community building M5.3. } \\
\text { Establish multiple project stages } \\
\text { M1.2.2, frequently monitor student } \\
\text { progress on wikis, and offer timely } \\
\text { feedback M5.2.3. This encourages } \\
\text { students to pause, review, reflect on } \\
\text { their process, and improve M5.1; it } \\
\text { also reduces instructors' time for } \\
\text { final evaluation } \\
\text { Offer frequent feedback to in- } \\
\text { progress projects (peer feedback, } \\
\text { instructors' feedback via face-to- } \\
\text { face interaction, messages, written } \\
\text { comments with assigned grade) } \\
\text { M5.2.2, M5.2.3, M6.2.2. }\end{array}$ & $\begin{array}{l}\text { Experts confirmed the challenge of } \\
\text { assessing individuals' community } \\
\text { building and proposed activity logs in } \\
\text { addition to tracking students' progress } \\
\text { frequently to enhance efficiency. } \\
\text { Another possibility is to use system- } \\
\text { generated data logs (installation } \\
\text { required on MediaWiki) to assess } \\
\text { individual contributions for large } \\
\text { classes. } \\
\text { Experts explained that as students adopt } \\
\text { the values of process-oriented learning } \\
\text { and open up to diverse perspectives in } \\
\text { the give-and-take culture, they become } \\
\text { willing to take advice and improve their } \\
\text { work. } \\
\text { Additionally, as multiple project stages } \\
\text { are established for complex projects, } \\
\text { students have opportunities to receive } \\
\text { feedback and improve before } \\
\text { completing projects. }\end{array}$ \\
\hline
\end{tabular}

\section{Acknowledgement}

This paper was developed and written based on the first author's dissertation (Lin, 2013). The authors would like to express gratitude to the instructors and students who participated in this study. Without David Gelb and Mike Jones's wisdom and support, this project would have been impossible to complete.

Received: September 5, 2020

Accepted: October 18, 2020

Published: January 8,2021

Guidance for wiki-supported collaborative learning and community knowledge building for an entire class: Enhancing learning environments during the COVID19 pandemic. Chun-Yi Lin and Charles M. Reigeluth. 
Lin, C.-Y., \& Reigeluth, C.M. (2020). Guidance for wiki-supported collaborative learning and community knowledge building for an entire class: Enhancing learning environments during the COVID19 pandemic. RED. Revista Educación a Distancia, 21(65). http://dx.doi.org/10.6018/red.447401

\section{Funding}

This research has not received any specific grant from funding agencies in the public, commercial or non-profit sectors.

\section{References}

Bereiter, C. (2002). Design research for sustained innovation. Cognitive Studies, Bulletin of the Japanese Cognitive Science Society, 9(3), 321-327. Retrieved from http://ikit.org/fulltext/2002Design_Research.pdf

Berthoud, L. \& Gliddon, J. (2018). Using wikis to investigate communication, collaboration and engagement in Capstone engineering design projects. European Journal of Engineering Education, 43(2), 247-263. doi: 10.1080/03043797.2017.1332574

Bold, M. (2006). Use of wikis in graduate course work. Journal of Interactive Learning Research, 17(1), 5-14. Retrieved from http://www.aace.org/pubs/jilr/

Bonk, C. J., Lee, M. M., Kim, N., \& Lin, M.-F. (2010). Wikibook transformations and disruptions: Looking back twenty years to today. In H. H. Yang, \& S. C-Y. Yuen (Eds.), Collective intelligence and e-learning 2.0: Implications of web-based communities and networking (pp.127-146). Hershey, PA: Information Science Reference.

Bruning, R. H., Schraw, G. J., Norby, M. M., \& Ronning, R. R. (2003). Problem solving and critical thinking. Cognitive psychology and instruction (4th ed.). Upper Saddle River, NJ: Pearson.

Cole, M. (2009). Using wiki technology to support student engagement: Lessons from the trenches. Computers \& Education, 52(1), 141-146. doi:10.1016/j.compedu.2008.07.003

Design-Based Research Collective. (2003). Design-based research: An emerging paradigm for educational inquiry. Educational Researcher, 32(1), 5-8. doi:10.3102/0013189X032001005

de Pedro Puente, X. (2007). New method using wikis and forums to evaluate individual contributions in cooperative work while promoting experiential learning: Results from preliminary experience. Paper presented at the International Symposium on Wikis, Montreal, Quebec, Canada.

de Pedro, X., Rieradevall, M., López, P., Sant, D., Piñol, J., Núñez, L., et al. (2006a). Writing documents collaboratively in higher education using traditional vs. wiki methodology

Guidance for wiki-supported collaborative learning and community knowledge building for an entire class: Enhancing learning environments during the COVID19 pandemic. Chun-Yi Lin and Charles M. Reigeluth. 
(I): QUALITATIVE results from a 2-year project study. Paper presented at the 4th International Congress of University Teaching and Innovation (IV CIDUI).

Retrieved from http://uniwiki.ourproject.org/Article+Wikis

de Pedro, X., Rieradevall, M., López, P., Sant, D., Piñol, J., Núñez, L., et al. (2006b). Writing documents collaboratively in higher education using traditional vs. wiki methodology (II): QUANTITATIVE results from a 2-year project study. Paper presented at the 4th International Congress of University Teaching and Innovation (IV CIDUI).

Retrieved from http://uniwiki.ourproject.org/Article+Wikis+2

Elgort, I., Smith, A. G., \& Toland, J. (2008). Is wiki an effective platform for group course work? Australasian Journal of Educational Technology, 24(2), 195-210.

Garrison, D. R., \& Akyol, Z. (2009). Role of instructional technology in the transformation of higher education. Journal of Computing in Higher Education, 21(1), 19-30. doi:10.1007/s12528-009-9014-7

Hemmi, A., Bayne, S., \& Land, R. (2009). The appropriation and repurposing of social technologies in higher education. Journal of Computer Assisted Learning, 25(1), 19-30. doi:10.1111/j.1365-2729.2008.00306.x

Johnson, D. W., \& Johnson, R. T. (1989). Cooperation and competition: Theory and research. Edina, MN: Interaction Book Company.

Lee, J.-Y., \& Reigeluth, C. M. (2003). Formative research on the heuristic task analysis process. Educational Technology Research and Development, 51(4), 5-24. doi:10.1007/BF02504541

Lee, J.-Y., \& Reigeluth, C. M. (2009). Heuristic task analysis on e-learning course development: A formative research study. Asia Pacific Education Review, 10(2), 169-181. doi:10.1007/s12564-009-9016-1

Lin, C.-Y. (2013). Instructional theory for using a class wiki to support collaborative learning in higher education (Doctoral dissertation). Indiana University Bloomington, IN. http://search.proquest.com/docview/1362257949

Lin, C.-Y., \& Reigeluth, C. M. (2016). Scaffolding wiki-supported collaborative learning for small-group projects and whole-class collaborative knowledge building. Journal of Computer Assisted Learning, 32(6), 529-547._https://doi.org/10.1111/jcal.12140

Lin, C.-Y., \& Reigeluth, C. M. (2019). Scaffolding learner autonomy in a wiki-supported knowledge building community and its implications for mindset change. British Journal of Educational Technology, 50(5), 2667-2684. _https://doi.org/10.1111/bjet.12713

Matthews, R. S., Cooper, J. L., Davidson, N., \& Hawkes, P. (2003). Building bridges between cooperative and collaborative learning. In J. L. Cooper, P. Robinson \& D. Ball (Eds.), Small group instruction in higher education: Lessons from the past, visions of the future. Stillwater, Oklahoma: New Forums Press.

Nichols, J. D., \& Miller, R. B. (1994). Cooperative learning and student motivation. Contemporary Educational Psychology, 19(2), 167-178. doi:10.1006/ceps.1994.1015

Guidance for wiki-supported collaborative learning and community knowledge building for an entire class: Enhancing learning environments during the COVID19 pandemic. Chun-Yi Lin and Charles M. Reigeluth. 
Panitz, T. (1996). A definition of collaborative vs. cooperative learning. Retrieved from http://www.londonmet.ac.uk/deliberations/collaborative-learning/panitz-paper.cfm

Reigeluth, C. M. (1999a). The elaboration theory: Guidance for scope and sequence decisions. In C. M. Reigeluth (Ed.), Instructional-design theories and models: A new paradigm of instructional theory (Vol. 2, pp. 425-453). Mahwah, NJ: Lawrence Erlbaum.

Reigeluth, C. M., Lee, J.-Y., Peterson, B., \& Chavez, M. (2000). Formative research on the heuristic task analysis. ERIC Document Reproduction Service. (ED455788). Retrieved from

http://eric.ed.gov/ERICWebPortal/search/detailmini.jsp?_nfpb=true\&_\&ERICExtSear ch_SearchValue_0=ED455788\&ERICExtSearch_SearchType_0=no\&accno=ED455788

Robertson, I. (2008). Learners' attitudes to wiki technology in problem based, blended learning for vocational teacher education. Australasian Journal of Educational Technology, 24(4), 425-441. Retrieved from http://www.ascilite.org.au/ajet/submission/index.php/AJET/index

Rienties, B., Tempelaar, D., Van den Bossche, P., Gijselaers, W., \& Segers, M. (2009). The role of academic motivation in computer-supported collaborative learning. Computers in Human Behavior, 25(6), 1195-1206. doi:10.1016/j.chb.2009.05.012

Saunders, W. M. (1989). Collaborative writing tasks and peer interaction. International Journal of Educational Research, 13(1), 101-112. doi:10.1016/0883-0355(89)90019-0

Schacht, P. (2007). The collaborative writing project. In S. Mader (Ed.), Using wiki in education (pp. 12-23). Retrieved from http://www.google.ca/url?sa=t\&source=web\&cd=14\&ved=0CC8QFjADOAo\&url=http s\%3A\%2F\%2Fwiki.umontreal.ca\%2Fdownload\%2Fattachments\%2F3693\%2FUsingWi kilnEducation_StewartMader.pdf\&rct=j\&q=using\%20wiki\%20in\%20education\&ei=qE pQTYT2GtDSgQftnKHODw\&usg=AFQjCNG4eTozTgRngdiFCASNXvgANyFWfA\&sig2=ag uDIpnNWdgVUEp5v_1b5g\&cad=rja

Trocky, N. M., \& Buckley, K. M. (2016). Evaluating the impact of wikis on student learning outcomes: An integrative review. Journal of professional nursing, 32(5), 364-376. doi: 10.1016/j.profnurs.2016.01.007

Wang, F., \& Hannafin, M. J. (2005). Design-based research and technology-enhanced learning environments. Educational Technology Research and Development, 53(4), 5-23. doi:10.1007/BF02504682

West, J. A., \& West, M. L. (2009). Using wikis for online collaboration: The power of the readwrite Web ( $1^{\text {st }}$ ed.). San Francisco: Jossey-Bass.

UNESCO (2020). Culture \& COVID-19: Impact and response tracker. Retrieved

from https://en.unesco.org/news/culture-covid-19-impact-and-response-tracker

Guidance for wiki-supported collaborative learning and community knowledge building for an entire class: Enhancing learning environments during the COVID19 pandemic. Chun-Yi Lin and Charles M. Reigeluth. 